\title{
$\bullet$ Factors Affecting Social Support and Resilience on Police Officer
}

\section{IJCRR \\ Section: Healthcare \\ ISI Impact Factor \\ (2019-20): 1.628 \\ IC Value (2019): 90.81 \\ $\operatorname{SJIF}(2020)=7.893$ \\ (c) (i) (3) \\ Copyright@IJCRR}

\section{ABSTRACT}

Introduction: According to survey the highest priority job with most stress on or off duty is the for the security and that is for the police officers. Since the police organization has clear hierarchical order between rigid command lines, conflict of opinions between bosses and co-workers, harassment of senior executives, and pressure for promotion can be factors of work-related stress.

Objective: The purpose of this study was to provide basic data on mental health by identifying factors affecting the resilience of police officer.

Method: With the consent of the Subject the data collection was done from October 1 to November 30, 2019. 150 participants were included in the final analysis. The demographic characteristics, resilience, and social support were considered in the questionnaire. The descriptive statistics, t-test, ANOVA, Pearson's correlation and multiple regression using SPSS 21.0 statistical program were used for analysis of the collected data.

Results: The results of this study showed that the difference in resilience, according to general characteristics as gender, place of psychological distress and gender, age, position, working department, total work experience and subjective health state in social support. Resilience showed a static positive correlation with social support, emotional support, informative support, material support, evaluation support.

Conclusion: Based on the above results, regression analysis showed that factors affecting resilience were gender, material support and emotional support the factors used in the analysis explained $30.5 \%$ of resilience.

Key Words: Social support, Resilience, Police officer, Health

\section{INTRODUCTION}

The police of Korea have been established for the 75th anniversary in 2020. The number of police officers in the country amounted to 10,364. Among them, 45,129 police officers $(41.2 \%)$ were police officers in Frontline and police box, a large number of police officers are working for public welfare. ${ }^{1,2}$ The police officer's main task is to protect the lives, bodies and property of the people, to prevent crime, to suppress and investigate, to collect police information, to control traffic, and to maintain common goodwill and order. ${ }^{3}$ About $41 \%$ of the current police officers work in frontline zones and police boxes, and the 112 reports are the first to report the incident and take action on the site. In the process, they exposed to risks and unpredictable outbreaks, which repeat- ed 24 hours a day, seven days a week, and work in constant tension. As you can see from this situation, police officers are suffering from heavy work such as arrest and handling of 112 reports and suffer from various stresses. ${ }^{3}$

According to the survey of job stress by occupations conducted by the National Employment Information Service in 2013, the highest priority job was the police officer. ${ }^{4}$ Also, police officers may suffer direct harm to their lives or bodies due to the nature of their work or take responsibility for the consequences of the measures are wrong. Therefore, police officers must have high psychological pressures and tensions from the moment they go to the scene of the incident to the end of all actions, including the arrest and a convoy of criminals after arrival. ${ }^{4}$

\section{Corresponding Author:}

Youngsoon Choi, Department of Nursing, Kangwon National University, Samcheck-si, Gangwon-do, 25949, Republic of Korea. Email: ysc615@hanmail.net

ISSN: 2231-2196 (Print)

Received: 20.11 .2020
ISSN: 0975-5241 (Online)

Revised: 22.12 .2020
Accepted: 02.01.2021
Published: 03.03 .2021 
As such, there are various risk factors and conflicts at the scene of the incident, and police officers are at the centre and no one can replace them. Police officers have to deal with these various risk factors and conflict relationships, and in complex and ambiguous situations, they are always required to respond quickly to situations and deal with crises, thus experiencing various conflicts and job stress. ${ }^{4}$ The police are constantly patrolling to prevent crimes and encounter terrible and cruel scenes in the violent incidents such as murders, struggling to pursue criminal arrests, and risk the injuries at the traffic enforcement and accident scenes. They are experiencing high levels of stress due to increasing civil infringement crimes and violent incidences, increasingly powerful incidents, citizens' rescue requests, and witnessing incidents. ${ }^{5,6}$

Since the police organization has clear hierarchical order between rigid command lines, conflict of opinions between bosses and co-workers, harassment of senior executives, and pressure for promotion can be factors of work-related stress; this can lead to conflicts between supervisors, colleagues and subordinates, or weaken fellowship. ${ }^{7,8}$ Personal stressors may also include family time and lack of personal leisure time, physical safety and health concerns, and adequacy of work. ${ }^{8}$ As the voice of concern for the mental health of police officers is increasing, there is little or no national measures or support for this. ${ }^{9}$ Police officers' job stress was associated with increased anxiety, depression, somatic symptoms, post-traumatic stress symptoms, psychological exhaustion, chronic pain, alcohol abuse, and inappropriate aggressive behaviour. ${ }^{10}$

Social support means "resources provided by others" in a broad sense. ${ }^{11}$ Caplan (1974) defined social support as a "continuous collection of individuals who provide opportunities for feedback to identify expectations of themselves and others. ${ }^{12}$ In the concept of social support, Park Ji-won (1985) included various dimensions such as social support network, support type, and support desire. Besides, they defined the degree of support, confidence, and confidence in their social relations that reflects the degree of support provided in real situations, the degree of recognition that they can provide through members of the social network, and the degree of satisfaction of support needs. ${ }^{13}$ The concept of social support is the act of mitigating the negative effects of stressful situations, which defined as positive resources that individuals can get from interpersonal relationships, and the social supporters include family members, friends, teachers, and colleagues. ${ }^{12}$

Social support acts as a major mechanism to enhance an individual's positive development and adaptive ability (attitude) by improving their various internal functions and protecting them from external negative influences. ${ }^{11}$ According to Wakjer, Michael, Stanley Wasserman \& Barry Well- man, social support acts as an indirect function to protect and cushion the individual from the stressful effects or negative effects of the problem they face, increasing the positive emotions of the individual regardless of the situation, and a direct function of improving general adaptation by increasing well-being and control over the environment. ${ }^{14}$ Resilience is all your effort to control your urges for effective adaptation when faced with a variety of stressful situations. ${ }^{15,16}$ Respond flexibly, without stiffness or frustration in stressful situations, it is a dynamic ability to return to the original level of self-control. ${ }^{15-17}$ Resilient people adapt well to stressful situations with high confidence and positive emotions, while less resilient people are persistent or distracted by excessive or under control. ${ }^{18}$ For example, when someone exposed to the same stressful situation, someone will quickly overcome it; some people may have difficulty in a state of maladjustment. In a dangerous situation that threatens mental health, protecting yourself and turning it into an opportunity for growth to increase your ability to move forward is a way to prevent risks such as depression. ${ }^{3}$

This resilience is a concept that focuses on the individual's ability and resources to adapt to the situation and flexibly, rather than individual defects or weaknesses. It can be inferred that in various circumstances, it is possible to overcome the problems caused by the flexible problem-solving ability and the negative emotions according to the situational needs. ${ }^{3}$ However, as a measure to mitigate the negative effects of police officers under stress, studies on social support and resilience are insufficient.

Therefore, this study confirms the degree of social support and resilience of police officers and the relationship between social support and resilience. Also, this study conducted to identify factors influencing resilience and to use them as basic data in establishing a support system for social support needed to improve the mental health of police officers.

\section{MATERIALS AND METHODS}

\section{Research design}

This study is descriptive research using structured questionnaires to investigate the effect of social support on the resilience of police officer.

\section{Subjects}

This study, conducted for a police officer in G city and $\mathrm{Y}$ city in Gangwondo Province. The purpose of this research understood and it conveniently extracted to those who voluntarily agreed to participate in the research. The number of samples was calculated by using $G^{*}$ Power 3.1.5 program for multiple regression analysis, the significance level was calculated as 0.05 , the power was 0.95 , 
the effect size was 0.15 , and the final sample size was 138 people. 160 copies distributed in consideration of the number of dropouts, and 155 copies collected. Among them, 150 data used for the final analysis except for five cases where the response was insufficient.

\section{Research tools}

\section{Social support}

Social support tools developed by Park were used. ${ }^{19}$ The tool consists of the subdomain of emotional support, informative support, material support, and evaluative support. 25 questions, a 5-point Likert scale, means that the higher the score, the higher the social support. The Cronbach's value in the study of Park was 0.95 , and the Cronbach's value by this study was 0.98 .

\section{Resillience}

Resilience means a combination of capabilities and characteristics that includes a process of dynamic interaction, allowing individuals to recover from their original state, adapt successfully and adapt to their physical condition despite stress or to interact dynamically. ${ }^{20}$ It was Baek translated the Resiliency measurement tool developed by Connor and Da vidson (K-CD-RISC: Korean Connor Da vidson Resilience Scale)..$^{21,22}$ The tool consists of five sub-factors: robustness, persistence, optimism, support, and spirituality. It was composed of a 5-point Likert scale with totally of 25 items. Cronbach's $\alpha$ value stood at 0.93 . Cronbach's $\alpha$ value in this study came to 0.94 .

\section{Data collection}

Data collection made through the one-to-one interview with each individual with a researcher and three research assis- tants, who trained in advance, from October 1, 2019, to November 30. A structured questionnaire used in subjects with the written consent of participating in the research. 160 copies distributed in consideration of the number of dropouts, and 155 copies collected. Among them, 150 data used for the final analysis except for five cases where the response was insufficient.

\section{Data analysis}

The collected data analyzed using the SPSS 21.0 program. The details are as follows. The collected data analyzed using the SPSS 21.0 program as follows. Resilience and social support level, according to the demographic characteristics of the subjects analyzed with descriptive statistics, t-test, ANOVA, and post-test used for Scheff's test. The correlations between resilience and social support analyzed using Pearson's correlation. The effects of the resilience analyzed by multiple regression.

\section{RESULTS}

\section{Differences in resilience and social support ac- cording to the characteristics of the subjects}

Resilience differences in general characteristics were statistically significant with is gender $(t=3.58, \mathrm{p}<0.001)$, place of psychological distress $(\mathrm{F}=3.43, \mathrm{p}<0.05)$. Social support differences in general characteristics were statistically significant with is gender $(\mathrm{t}=-2.52, \mathrm{p}<0.05)$, age $(\mathrm{F}=13,65$ $\mathrm{p}<0.001)$, position $(\mathrm{F}=7.61, \mathrm{p}<0.001)$, working department $(\mathrm{F}=3.37, \mathrm{p}<0.05)$, total work experience $(\mathrm{F}=10.87, \mathrm{p}<0.001)$, subjective health state $(\mathrm{F}=2.71, \mathrm{p}<0.05)$ as shown in Table 1 .

Table 1: The difference in resilience and social support of according to general characteristics $(\mathrm{N}=150)$

\begin{tabular}{|c|c|c|c|c|c|c|c|}
\hline \multirow[b]{2}{*}{ Characteristics } & \multirow{2}{*}{\multicolumn{2}{|c|}{ Categories }} & \multirow[b]{2}{*}{$\mathbf{n}(\%)$} & \multicolumn{2}{|c|}{ Social support } & \multicolumn{2}{|c|}{ Resilience } \\
\hline & & & & $\mathrm{M} \pm \mathrm{SD}$ & $\begin{array}{l}\text { t/F(p), } \\
\text { Scheffe }\end{array}$ & $\mathrm{M} \pm \mathrm{SD}$ & $\begin{array}{l}\text { t/F(p), } \\
\text { Scheffe }\end{array}$ \\
\hline \multirow{2}{*}{ Gender } & Male & & $123(82)$ & $85.98 \pm 16.59$ & \multirow{2}{*}{$-2.52(0.013)$} & $90.09 \pm 10.60$ & \multirow{2}{*}{$3.58(<0.001)$} \\
\hline & Female & & $27(18)$ & $12.71 \pm 12.71$ & & $81.96 \pm 11.09$ & \\
\hline \multirow{4}{*}{ Age(year) } & $20 \sim 29$ & $\mathrm{a}$ & $31(20.7)$ & $98.25 \pm 13.29$ & \multirow{4}{*}{$\begin{array}{c}13.65(<0.001) \\
a>b, c>d\end{array}$} & $90.87 \pm 11.91$ & \multirow{4}{*}{$1.12(0.342)$} \\
\hline & $30 \sim 39$ & b & $53(35 \cdot 3)$ & $89.58 \pm 14.45$ & & $86.60 \pm 10.91$ & \\
\hline & $40 \sim 49$ & d & $42(28)$ & $84.88 \pm 15.70$ & & $88.80 \pm 10.87$ & \\
\hline & $50 \sim 59$ & c & $24(16)$ & $73.75 \pm 14.00$ & & $89.91 \pm 10.76$ & \\
\hline \multirow{5}{*}{ Position } & Constable & a & $30(20)$ & $98.76 \pm 14.23$ & \multirow{5}{*}{$\begin{array}{c}7.61(<0.001) \\
a>b, e, c>d\end{array}$} & $88.96 \pm 11.26$ & \multirow{5}{*}{$1.10(0.355)$} \\
\hline & Corpor & b & $29(19.4)$ & $91.10 \pm 15.34$ & & $88.86 \pm 9.62$ & \\
\hline & Sergeant & c & $41(27.3)$ & $84.63 \pm 14.90$ & & $85.78 \pm 12.41$ & \\
\hline & Lieutenant & d & $45(30)$ & $80.31 \pm 15.70$ & & $90.75 \pm 10.99$ & \\
\hline & Inspector & e & $5(3 \cdot 3)$ & $87.52 \pm 10.00$ & & $89.60 \pm 4.39$ & \\
\hline
\end{tabular}


Table 1: (Continued)

\begin{tabular}{|c|c|c|c|c|c|c|c|}
\hline \multirow[b]{2}{*}{ Characteristics } & \multirow{2}{*}{\multicolumn{2}{|c|}{ Categories }} & \multirow[b]{2}{*}{$\mathbf{n}(\%)$} & \multicolumn{2}{|c|}{ Social support } & \multicolumn{2}{|c|}{ Resilience } \\
\hline & & & & $\mathrm{M} \pm \mathrm{SD}$ & $\begin{array}{l}\text { t/F }(p) \\
\text { Scheffe }\end{array}$ & $\mathrm{M} \pm \mathrm{SD}$ & $\begin{array}{l}\text { t/F }(p) \\
\text { Scheffe }\end{array}$ \\
\hline \multirow{5}{*}{ Working department } & Constabulary & $\mathrm{a}$ & $40(26.7)$ & $81.05 \pm 18.75$ & \multirow{5}{*}{$\begin{array}{l}3.37(0.011) \\
c>b, e, d>a\end{array}$} & $91.00 \pm 13.01$ & \multirow{5}{*}{$2.07(0.870)$} \\
\hline & Traffic & $\mathrm{b}$ & $7(4 \cdot 7)$ & $92.00 \pm 9.98$ & & $82.85 \pm 8.15$ & \\
\hline & Investigation & c & $71(47 \cdot 3)$ & $91.78 \pm 14.64$ & & $89.49 \pm 9.83$ & \\
\hline & Security & d & $15(10)$ & $83.53 \pm 14.57$ & & $86.60 \pm 10.99$ & \\
\hline & Etc & e & $17(11.3)$ & $86.64 \pm 15 \cdot 34$ & & $83.64 \pm 10.97$ & \\
\hline \multirow{4}{*}{$\begin{array}{l}\text { Total work experi- } \\
\text { ence } \\
\text { (years) }\end{array}$} & $<5 \mathrm{yr}$ & $\mathrm{a}$ & $55(36.7)$ & $96.60 \pm 14.05$ & \multirow{4}{*}{$\begin{array}{c}10.87(<0.001) \\
a>b>c, d\end{array}$} & $89.38 \pm 10.55$ & \multirow{4}{*}{$2.10(0.102)$} \\
\hline & $6 y r \sim 10 y r$ & $\mathrm{~b}$ & $17(11.3)$ & $88.76 \pm 14.18$ & & $84.76 \pm 10.59$ & \\
\hline & 11yr 20yr & c & $49(32.7)$ & $84.06 \pm 14.11$ & & $87.06 \pm 11.12$ & \\
\hline & $21 y r \sim 30 y r$ & d & $29(19.3)$ & $77 \cdot 34 \pm 17 \cdot 71$ & & $92.13 \pm 11.75$ & \\
\hline \multirow{4}{*}{$\begin{array}{l}\text { Subjective health } \\
\text { state }\end{array}$} & Very healthy & $\mathrm{a}$ & $16(10.7)$ & $89.87 \pm 21.65$ & \multirow{4}{*}{$\begin{array}{c}2.71(0.047) \\
b>a, c>d\end{array}$} & $94.50 \pm 14.03$ & \multirow{4}{*}{$2.27(0.082)$} \\
\hline & $\begin{array}{l}\text { General } \\
\text { Health }\end{array}$ & $\mathrm{b}$ & $57(38)$ & $91.22 \pm 17.06$ & & $89.36 \pm 11.59$ & \\
\hline & Usually & c & $67(44.7)$ & $85.19 \pm 13.45$ & & $86.89 \pm 9.54$ & \\
\hline & Slight disease & $\mathrm{d}$ & $10(6.6)$ & $78.30 \pm 15.11$ & & $86.70 \pm 10.89$ & \\
\hline \multirow{6}{*}{ Stress relief } & \multicolumn{2}{|c|}{ Talk with colleagues } & $62(41.3)$ & $90.83 \pm 16.76$ & \multirow{6}{*}{$2.09(0.070)$} & $88.24 \pm 11.44$ & \multirow{6}{*}{$0.82(0.532)$} \\
\hline & \multicolumn{2}{|c|}{ Talk to your boss } & $3(2)$ & $82.33 \pm 15.94$ & & $86.00 \pm 11.78$ & \\
\hline & Hobby & & $49(32.7)$ & $85.85 \pm 14.20$ & & $90.59 \pm 10.81$ & \\
\hline & Alcohol & & $20(13.4)$ & $79.65 \pm 15.93$ & & $84.85 \pm 9.20$ & \\
\hline & Talk to fam & & $8(5 \cdot 3)$ & $95 \cdot 50 \pm 18.48$ & & $89.25 \pm 13.87$ & \\
\hline & No solutic & & $8(5 \cdot 3)$ & $85.75 \pm 17.77$ & & $89.50 \pm 12.17$ & \\
\hline \multirow{3}{*}{$\begin{array}{l}\text { Place of psychologi- } \\
\text { cal distress }\end{array}$} & medical clinic & $\mathrm{a}$ & $4(2.7)$ & $94.25 \pm 6.02$ & \multirow{3}{*}{$1.66(0.192)$} & $93.25 \pm 8.38$ & \multirow{3}{*}{$\begin{array}{c}3.43(0.035) \\
a>c>b\end{array}$} \\
\hline & $\begin{array}{c}\text { oriental } \\
\text { medical clinic }\end{array}$ & $\mathrm{b}$ & $5(3.3)$ & $75.80 \pm 11.51$ & & $76.60 \pm 6.22$ & \\
\hline & None & c & 141(94) & $87.75 \pm 16.45$ & & $88.92 \pm 11.08$ & \\
\hline \multirow{2}{*}{$\begin{array}{l}\text { Consider counseling, } \\
\text { treatment help }\end{array}$} & Yes & & $35(23.3)$ & $87.14 \pm 16.64$ & \multirow{2}{*}{$-0.159(0.874)$} & $87.00 \pm 12.70$ & \multirow{2}{*}{$-0.99(0.322)$} \\
\hline & No & & $115(76.7)$ & $87.64 \pm 16.22$ & & $89.13 \pm 10.58$ & \\
\hline
\end{tabular}

\section{Resilience and social support level of subjects}

The level of resilience was $88.63 \pm 11.10$ on the scale of 125 points. The level of social support was $87.52 \pm 16.26$ on the scale of 125 . In the subdomain, emotional support was $24.80 \pm 4.82$ on the scale of 35 , informative support was $21.24 \pm 4.13$ on the scale of 30 , material support was $20.44 \pm 4.17$ on the scale of 30 , and evaluative support was $21.03 \pm 4.34$ on the scale of 30 points as shown in Table 2 .

Table 2: Level of resilience and social support $(\mathrm{N}=150)$

\begin{tabular}{lcc} 
Variable & Range & M \pm SD \\
Resilience & $25 \sim 125$ & $88.63 \pm 11.10$ \\
Social support & $25 \sim 125$ & $87.52 \pm 16.26$ \\
Emotional support & $7 \sim 35$ & $24.80 \pm 4.82$ \\
Informative support & $6 \sim 30$ & $21.24 \pm 4.13$ \\
Material support & $6 \sim 30$ & $20.44 \pm 4.17$ \\
Evaluative support & $6 \sim 30$ & $21.03 \pm 4.34$ \\
\hline
\end{tabular}

\section{Correlation between the subject's resilience and social support}

The resilience was a significant positive correlated with social support $(\mathrm{r}=0.376, \mathrm{p}<0.001)$, emotional support $(\mathrm{r}=0.358$, $\mathrm{p}<0.001)$, information support $(\mathrm{r}=0.309, \mathrm{p}<0.001)$, material support $(\mathrm{r}=0.386, \mathrm{p}<0.001)$, and evaluation support $(\mathrm{r}=0.346$, $\mathrm{p}<0.001)$. Social support was significant positive correlated with emotional support ( $r=0.907, \mathrm{p}<0.001)$, information support $(\mathrm{r}=0.952, \mathrm{p}<0.001)$, material support $(\mathrm{r}=0.933, \mathrm{p}<0.001)$, and evaluation support $(\mathrm{r}=0.935, \mathrm{p}<0.001)$. Emotional support was significantly positively correlated with information support $(\mathrm{r}=0.838, \mathrm{p}<0.001)$, material support $(\mathrm{r}=0.743, \mathrm{p}<0.001)$, and evaluation support $(\mathrm{r}=0.773, \mathrm{p}<0.001)$. Emotional support was a significant positive correlated with material support $(\mathrm{r}=0.875, \mathrm{p}<0.001)$ and evaluation support $(\mathrm{r}=0.843, \mathrm{p}<0.001)$. Material support was a significant positive correlated with evaluation support $(\mathrm{r}=0.875, \mathrm{p}<0.001)$ as shown in Table 3 . 
Table 3: Correlation between the subjects' social resilience and social support $(\mathrm{N}=\mathbf{1 4 4})$

\begin{tabular}{lcccccc} 
Variable & Resilience & Social support & $\begin{array}{c}\text { Emotional } \\
\text { support }\end{array}$ & Informative support & $\begin{array}{c}\text { Material } \\
\text { support }\end{array}$ & $\begin{array}{c}\text { Evaluative } \\
\text { support }\end{array}$ \\
Resilience & 1 & & & & \\
Social support & $0.376^{* *}$ & 1 & & & \\
Emotional support & $0.358^{* *}$ & $0.907^{* * *}$ & 1 & 1 & \\
Informative support & $0.309^{* * *}$ & $0.9525^{* *}$ & $0.83^{* * *}$ & $0.875^{* * *}$ & 1 & 1 \\
Material support & $0.386^{* * *}$ & $0.933^{* * *}$ & $0.743^{* * *}$ & $0.875^{* * *}$ & 1 \\
Evaluative support & $0.346^{* * *}$ & $0.935^{* * *}$ & $0.773^{* * *}$ & $0.843^{* *}$ & \\
\hline
\end{tabular}

${ }^{*} p<0.05,{ }^{* *} p<0.001$

\section{Factors affecting the resilience}

Before the regression analysis, tolerance and Variance Inflation Factor (VIF) values examined to see whether multicollinearity occurred between the variables, as a result, the dispersion limit value is greater than 0.1 in both 0.42 to 0.93 , and the dispersion expansion value is 1.07 to 2.26 , there is no problem of multicollinearity. As a result of the multiple regression of the gender, working department, total work experience, emotional support and material support, Factors affecting resilience in gender $(\beta=-0.307, p<0.001)$, material support $(\beta=0.301, p<0.05)$ and emotional support $(\beta=0.269$, $\mathrm{p}<0.05$ ) were statistically significant. In particular, the gender analysed as harming the resilience, and the resilience explanatory power of the factors used in the analysis was $30.5 \%$ as shown in Table 4 .

Table 4: Factors affecting the hope of subjects $(\mathrm{N}=144)$

\begin{tabular}{|c|c|c|c|c|c|}
\hline Variable & B & SE & $\boldsymbol{\beta}$ & $\mathbf{t}$ & $\mathbf{P}$ \\
\hline (Constant) & 68.400 & 6.401 & & 10.685 & 0.000 \\
\hline Gender & -8.859 & 2.089 & -0.307 & -4.242 & 0.000 \\
\hline $\begin{array}{l}\text { Working } \\
\text { department }\end{array}$ & -1.174 & 0.619 & -0.134 & -1.897 & 0.060 \\
\hline $\begin{array}{l}\text { Total work } \\
\text { experience }\end{array}$ & 1.427 & 0.748 & 0.150 & 1.907 & $0.05^{8}$ \\
\hline $\begin{array}{l}\text { Emotional } \\
\text { support }\end{array}$ & 0.619 & 0.242 & 0.269 & 2.555 & 0.012 \\
\hline \multirow{2}{*}{$\begin{array}{l}\text { Material } \\
\text { support }\end{array}$} & 0.802 & 0.273 & 0.301 & 2.934 & 0.004 \\
\hline & $\begin{array}{c}\text { Adj } \\
\mathrm{R}^{2}=0.328\end{array}$ & $\begin{array}{c}\mathrm{R}^{2}= \\
0.305\end{array}$ & $F=14.06$ & $P<0.001$ & \\
\hline
\end{tabular}

\section{DISCUSSION}

This study conducted to investigate factors affecting resilience for police officers in $\mathrm{C}$ and $\mathrm{Y}$ districts in Gangwon-do and to explain the relationship between social support and resilience. As a result of this study, the social support of police officers was $87.52 \pm 16.26$ based on 125 points, and the social support according to general characteristics showed statistically significant differences in gender $(t=-2.52, p$ $<0.05)$ and age $(\mathrm{F}=13)$. , $65 \mathrm{p}<0.001)$, job title $(\mathrm{F}=7.61$, $p<0.001)$, department $(F=3.37, p<0.05)$, years of service $(\mathrm{F}=10.87, \mathrm{p}<0.001)$, subjective health status $(\mathrm{F}=2.71, \mathrm{p}$ $<0.05)$.

The detailed items, showing significant differences in social support are as follows. It was found that women were higher in gender, age was higher than those in their $40 \mathrm{~s}$ or $50 \mathrm{~s}$ in their 20s, higher in higher ranks, higher in police departments than in the district, and higher in fewer working years. Besides, the better the health status, the higher the social support.

In the mid-1970s, when preventive medicine emerged, social support began to draw attention as an environmental factor, as the need for new alternatives other than the physical and psychological factors that were previously raised about job stress was raised. Time. ${ }^{7}$ Currently, social support is widely used as a mediating factor to alleviate social problems from psychological well-being of an individual to stress, mental disorder, sexual violence, alcohol and substance abuse, senile dementia, cancer, bereavement, family dissolution, divorce, and death. ${ }^{6}$

Studies related to social support have been studied in various fields, but relatively few studies have been conducted with police officers. Kim Jong-gil found that evaluative support, a detailed item of evaluative support in the study of the impact on police post-traumatic stress disorder, reduces post-traumatic stress disorder, material support to support the necessary tools has been shown to further increase post-traumatic stress symptoms. ${ }^{6}$ A study by Kaufman and Beehr found that social support not only serves as a buffer for the negative job stress of police officers but also positively affects job satisfaction and psychological well-being. ${ }^{24}$

In the results of research on the social support of co-workers perceived by police officers, police officers found that social support from colleagues who best understand their grievances has the greatest impact on overcoming post-traumatic stress disorder, there has been conflicting research finding that social support from family members, friends, etc. outside the police organization helps overcome post-traumatic stress disorder. In the study of the influence of the support 
of the boss by Baruch-Feldman et al., social support had a positive effect on job satisfaction. In particular, contrary, research has shown that support by a work boss has a high positive effect on job satisfaction..$^{25}$

The police officers have a strong hierarchy and compulsory organizational attributes, and despite the heavy work, the group with high social support shows a rise in job satisfaction. It should be sought to strengthen social support so that job stress factors do not lower job satisfaction. ${ }^{23,24}$ According to the report contents of the relationship between stress coping method and happiness and unhappiness, the more people who pursue problem-oriented coping and social support, which are active stress-coping methods, feel that happiness is higher, and passive coping does not increase happiness. ${ }^{26}$

In a study by Hwang, social support showed a significant moderating effect in the relationship between stress and exhaustion, and the emotion-oriented coping method hurt controlling job stress by increasing exhaustion in controlling job stress. Also, it was reported that the group with high job stress level did not have the effect of promoting emotion-oriented coping. ${ }^{27}$ In this study, the resilience of police officers was $88.63 \pm 11.10$ based on 125 points. Resilience according to general characteristics showed statistically significant differences in gender $(\mathrm{t}=3.58, \mathrm{p}<0.001)$ and places visited by stress or psychological distress $(\mathrm{F}=3.43, \mathrm{p}<0.05)$.

People may have different reactions and reactions to stress due to their personality traits. In particular, in measuring job stress, the ability to deal with stress varies from person to person, so resilience role-plays an important role in resolving and managing job stress. ${ }^{28}$ The fundamental purpose of researching the resilience of the police should be implemented a lot to find a way to maximize organizational performance by associating the characteristics of the organization and its members. ${ }^{23}$ In Korea, for the first time in 2016, Lee's examined the resilience of police officers, subsequently, in 2017, research on Lee and Kim and Kwon and Joo conducted a full-scale study on the resilience of the police. ${ }^{3,23}$ Although it is not much later compared to previous studies in foreign countries, it is possible to effectively manage general stress and job stress through analysis of resilience, which is a method to recognize and control the severity of job stress effectively. In a previous study on resilience, resilience affected job stress, job satisfaction, and organizational commitment. Unfortunately, there have been few studies of resilience in the police..$^{28}$ Among them, a study by Kwon and Joo showed that resilience affects the police, ${ }^{23}$ Kim's study proved that positive among the factors of the resilience of the police is an important factor in managing job exhaustion. ${ }^{29}$

In previous studies, social support performed an important role in promoting individual mental health and has a positive effect on the formation of resilience, ${ }^{26}$ and reported a significant correlation between the police officer's social sup- port and resilience..$^{22}$ In this study, social support was found to have a positive correlation with resilience $(r=0.376, p$ $<0.001$ ), and which is a subdomain of social support was emotional support ( $r=0.907, p<0.001$ ), informational support $(\mathrm{r}=0.952, \mathrm{p}<0.001)$, material support $(\mathrm{r}=0.933$, $\mathrm{p}$ $<0.001)$, evaluative support $(\mathrm{r}=0.935, \mathrm{p}<0.001)$ showed a significant positive correlation. This is consistent with the study that social support reduces the negative effects of job stress and positively affects both physical and mental status. ${ }^{30}$

Today, stress refers to the forces, pressures, and strong influences acting on humans or objects, and life or object exerted by force creates tension to maintain integrity against external pressure. That is, stress includes two meanings of external pressure and tension against it. Specifically, external pressure is called a stressor, and reaction to return to the original state is called stress. ${ }^{31}$

When this stress is increased, it causes mental and physical problems. Besides, according to the results of recent studies, the damage has been seriously caused by adversely affecting organizational productivity, organizational convergence, and organizational commitment. Even the excessive cost is spent to solve the stress, and the problems caused by stress in society are both serious in terms of quantity and quality. ${ }^{28}$

As a result, factors affecting resilience in gender $(\beta=-0.307$, $p<0.001)$, material support $(\beta=0.301, p<0.05)$, and emotional support $(\beta=0.269, \mathrm{p}<0.05)$ showed statistically significant results. In particular, gender was found to harm resilience, and the resilience explanatory power of the factors used in the analysis was $30.5 \%$. Degradation of resilience can cause psychological and mental health problems for individuals. ${ }^{24}$ Therefore, continuous research and efforts on how to improve the resilience of police officers needed.

\section{CONCLUSION}

This study attempted to identify factors influencing the resilience of police officers, and in particular, the relationship between social support and resilience and factors affecting resilience.

Based on the results of this study, to make the following suggestions.

First, research and attention to factors that affect the resilience of police officers needed.

Second, follow-up studies on the relationship between the police officer's social support and resilience needed, and the effects of social support needed.

Third, research and attention on the development and application of an arbitration program for improving the resilience of police officers needed. 


\section{Acknowledgment: NIL}

\section{Conflict of Interest: NIL}

Source of Funding: NIL

\section{REFERENCES}

1. Lee SH, Kim DH. The relation of job stress and depression of police officers who worked in local patrol division: Focusing on the moderating effects of resilience. Korean Asso. Police Sci Rev 2017;16(3):281-310.

2. Park YJ. High stress job. National Police Agency. Korea. 2013.

3. Park SS. A study on the effect of stress on the turnover of police. Korean Assoc Pub Safety Crim Justi 2002;13:99-135.

4. Kim JH, Kim JK. The relation of a type of traumatic events and posttraumatic stress disorder (PTSD) symptoms of police officers: focusing on the moderating effects of stress coping style. Korean Police Stud Rev 2013;12(3):27-50.

5. Kim SY, Gu JT, Yoon GC. Analysis of job stress levels and causal factors of front line police officers. Korean J Public Admin 2002;41(1):123-147.

6. Joseph JK, Nagarajamurthy B. Stress in police officers. Int Org Sci J Humanities Soc Sci 2014;19(10):39-40.

7. Lee JH. Effect of police officer's stress coping strategy on job stress and attitudes toward seeking professional counseling. Unpublished master's thesis). Kyonggi University, Kyonggi, Korea. 2013:84.

8. Gershon RR, Lin S, Li X. Work stress in aging police officers. J. Occupat Env Med 2002;44(2):160-167.

9. Lee KJ. Effect of social support to baby boomer on self-efficacy and retirement attitude (Doctoral dissertation). Daegu Haany University. Gyeongsangbukdo. Available from http://www. riss. kr/link. 2015:96.

10. Jang DSL. An analysis of influence of self-efficacy and social support on job satisfaction and organizational commitment. (Doctoral dissertation). Kookmin University. Korea 2016:11.

11. Lim YH. The mediating effect of career decision-making selfefficacy on the relationship between social support awareness and career preparation behavior of career-break women. Master's Thesis. Korea University. Korea. 2012:89.

12. Ryu JS. The structural relationships among social support, family resilience, self-determination, commitment to career choice and career preparation behavior of undergraduate students. The Graduate School Chungbuk National University. 2012:131.

13. Kang MH, Lee SY. The mediating effects of hope and egoresilience on the relationship between adolescents' academic stress and psychological well-being. Korean J Youth Stud 2013 Jun;20(20):265-293.

14. Block JH, Block J. The role of ego-control and ego-resiliency in the organization of behavior. In Minnesota symposia on child psychology. 1980;13:39-101.
15. Howard S, Johnson B. Tracking student resilience. Children Australia. 1999;24(3):14-23.

16. Block J, Kremen AM. IQ and ego-resiliency: conceptual and empirical connections and separateness. J Pers Soc Psych 1996;70(2):349.

17. Park JW. A study to development a scale of social support. Unpublished doctoral dissertation, Yonsei University, Seoul. 1985.

18. Lee KH, Lee SW. Concept analysis of resilience. Korean J Stress Res 2005;13(1):9-18.

19. Baek HS, Lee KU, Joo EJ, Lee MY, Choi KS. Reliability and validity of the Korean version of the Connor-Davidson Resilience Scale. Psychiatry investigation. 2010;7(2):109.

20. Connor KM, Davidson JR. Development of a new resilience scale: The Connor-Davidson resilience scale (CD-RISC). Depression Anxiety 2003;18(2):76-82.

21. Bae JM. The relationships among job stressors, job satisfaction and organizational commitment of police officials-focusing on moderating effects of social support. Fire Sci Engg 2014;28(6):99-107.

22. Yoon, HS. The mediating effect of social support on the relationship between ego-resiliency and job enthusiasm in the police. Police Sci Inst 2017;31(3):311-350.

23. Kwon HR, Joo JJ. Validation of police officer Ego-resilience scales \& measurement. KAPSR 2017;19(19):245-273.

24. Kaufmann GM, Beehr TA. Interactions between job stressors and social support: Some counterintuitive results. J Appl Psychiat. 1986;71(3):522.

25. Baruch-Feldman C, Brondolo E, Ben-Dayan D, Schwartz J. Sources of social support and burnout, job satisfaction, and productivity. J Occupat Health Psychol 2002;7(1):84.

26. Lee, JY., Choi YY. The effect of cognitive emotion regulation and stress coping strategy on psychological well-being of college students: mediated by social support. Counsel Res 2012;13(3):1481-1499.

27. Hwang IH, Lee YH. Influences of police officers' job stress and traumatic stress on burnout. Korean J Psychol Gen 2012;31(4):1115-1138.

28. Kim KK. A study on influence of police officer's job stress on organizational commitment based on resilience. PhD's Thesis. Daegu University. Korea 2019:144.

29. Kim SH. The relative influence of job stress on burnout of police officers. The Korean Ass. Police Sci Rev 2014;48:3-25.

30. Cohen S, Hoberman HM. Positive events and social supports as buffers of life change stress 1. J App Soc Psychol 1983;13(2):99125.

31. Jeong CW. A study on job stress management of police officers - Focusing on personality-oriented self-management. Police Welfare Studies 2017;5(2):241-266. 